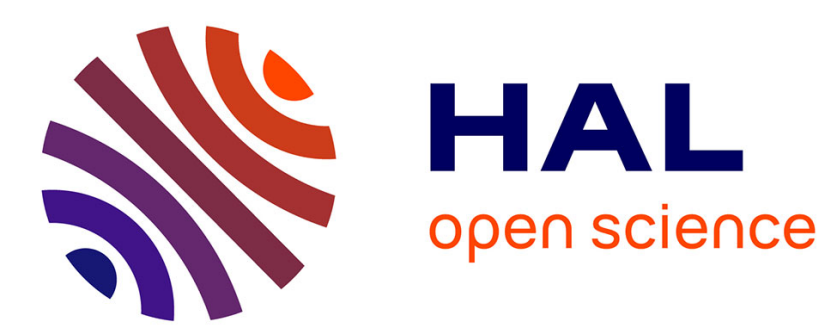

\title{
In-situ quartz microbalance study of the electrosynthesis of poly(3-methylthiophene)
}

S. Servagent, E. Vieil

\section{To cite this version:}

S. Servagent, E. Vieil. In-situ quartz microbalance study of the electrosynthesis of poly(3methylthiophene). Journal of electroanalytical chemistry and interfacial electrochemistry, 1990, 280

(1), pp.227-232. 10.1016/0022-0728(90)87101-O . hal-02157981

\section{HAL Id: hal-02157981 \\ https://hal.science/hal-02157981}

Submitted on 21 Jun 2019

HAL is a multi-disciplinary open access archive for the deposit and dissemination of scientific research documents, whether they are published or not. The documents may come from teaching and research institutions in France or abroad, or from public or private research centers.
L'archive ouverte pluridisciplinaire HAL, est destinée au dépôt et à la diffusion de documents scientifiques de niveau recherche, publiés ou non, émanant des établissements d'enseignement et de recherche français ou étrangers, des laboratoires publics ou privés. 


\title{
In-situ quartz microbalance study of the electrosynthesis of poly( 3- methylthiophene)
}

\author{
S. Servagent and E. Vieil \\ Electrochimie Moléculaire, Loboratoire de Chimie, Département de Recherche \\ Fondamenlale, Centre d'Etudes Nucléaires de Grenoble, SSX, 38041 Grenoble (France).
}

\section{INTRODUCTION}

It is widely recognized that the mass of a conducting polymer depends on its redox state. This results from the compensation of electrical charge variations which is accomplished by the movement of ions into and out of the polymer. Electrogravimetry is thus of great interest for the study of such materials and allows the determination not only of the mass variation due to ionic migration during an electrochemical doping-dedoping process but also of the mass variation created by monomer deposition during the synthesis [1,2]. The purpose of our investigation was to separate the two processes by studying the electropolymerization of poly(3-methylthiophene) (PMT) carried out by cyclic voltammetry using a Quartz Crystal Microbalance (QCM). The QCM is an extremely sensitive technique capable of measuring mass changes in the nanogram range [3] occurring during in-situ electrochemical and gravimetric experiments [4-8].

We have used this technique in order to assess two different properties: firstly, to measure the doping level of the PMT film through the mass variation which occurs during one cycle, and secondly, to establish the mass-charge relation as the polymerization proceeds.

\section{EXPERIMENTAL}

We used a commercial AT-cut quartz crystal of $10 \mathrm{MHz}$, from International Crystal Manufacturing Company Inc., Oklahoma City, each face of which had been precoated with a gold vacuum deposition to a thickness of $90 \mathrm{~nm}$.

The oscillator-potentiostat circuit was similar to the one described by Bruckenstein and Shay [9]. The apparatus was composed of an EGG PAR 173 potentiostat monitored by an EGG PAR 175 programmer connected to a plotter. The quartz frequency was initially converted to a voltage and then recorded on a digital oscilloscope (Nicolet 2090), while measuring simultaneously the charge with an EGG PAR 179 coulometer. All the data were transferred to an HP 9836 computer, and then treated in order to convert the frequency change Af to a mass change, following the Sauerbrey equation [3]:

$\Delta \mathrm{f}=-2.2610^{-6} \mathrm{f}^{2} \Delta \mathrm{m} / \mathrm{A}$

where $\Delta \mathrm{f}$ and $\mathrm{f}$ (the fundamental frequency of an AT-cut quartz crystal) are expressed in $\mathrm{Hz}$, $\Delta \mathrm{m}$ (the superficial mass) in $\mathrm{g}$, and $\mathrm{A}$ (the electrode area) in $\mathrm{cm}^{2}$.

The electrochemical cell is depicted in Fig. 1. In order to avoid possible problems linked to the high viscosity of the solvents generally used for the synthesis of PMT, such as propylene carbonate and nitrobenzene, we carried out our experiments in acetonitrile. A typical 
electropolymerization experiment was carried out in a solution of $0.1 \mathrm{~mol} \mathrm{drn}^{-3}$ in 3methylthiophene and $0.1 \mathrm{~mol} \mathrm{dm}^{-3}$ in $\mathrm{LiClO}_{4}$, in acetonitrile which had been distilled from $\mathrm{P}_{2} \mathrm{O}_{5}$ under argon. The solution, prepared in a dry box under an argon atmosphere, was manipulated quickly so as to avoid oxygen diffusion, since no nitrogen could be purged in the electrochemical cell. The electrochemical synthesis was carried out by cyclic voltammetry from $-0.1 \mathrm{~V}$ to $1.3 \mathrm{~V}$ versus an $\mathrm{Ag}$ wire at a scan rate of $50 \mathrm{mV} \mathrm{s}^{-1}$.

\section{RESULTS}

Figure 2 shows the mass and charge variations versus cycle number, obtained during the early stages of synthesis. The voltammograms, recorded during the fifth cycle, shows the classical irreversible monomer oxidation peak at $1.3 \mathrm{~V}$ vs. Ag. The resonance frequency undergoes a shift of $600 \mathrm{~Hz}$ during the experiment, which is very small with respect to the fundamental frequency of $10 \mathrm{MHz}$. Thus, the approximation of considering the polymer layers as a rigid film is relevant $[6,10]$.

We observe several phenomena in Fig. 2:

(1) A relative mass change for each cycle that we call "mass activity" due to the movement of ionic species (by analogy with electroactivity).

(2) A mass change involving the quantity of monomer deposited on the gold electrode. The slope ( $\mathrm{Y}$ of the mass versus cycle number curve is constant for the early cycles.

(3) A change in the slope (Y after the tenth cycle, while the slope $p$ of the charge curve remains constant; this implies a different polymerization process which we shall discuss later on.

Figure 3 shows the average mass variation $\Delta \mathrm{m}$ and charge variation $\Delta \mathrm{Q}$, calculated on the first five cycles, versus potential ( $\Delta \mathrm{m}$ and $\Delta \mathrm{Q}$ are corrected from the respective slopes $\alpha$ and $\beta$ ). For potentials lower than $0.4 \mathrm{~V}$, no mass changes are measured, indicating that no polymerization occurs. Above $0.4 \mathrm{~V}$, the mass increase follows the increase in charge until the charge reaches its maximum at $\mathrm{E}=1.06 \mathrm{~V}$. The mass variation corresponds not only to the quantity of monomer deposited during one cycle but also to the number of counter-anions required to neutralize electrically the film already deposited during the previous cycles. The polymerization mechanism is known to involve two electrons per mole of monomer unit and since the polymer is produced in its oxidized state, a fractional charge $\delta$ per monomer is needed for the doping process [11]. The value of the amount of charge $\delta$ varies, according to many authors [12], between 0.2 and 0.5 mole of electrons per mole of monomer, depending on the anion and reaction conditions. The electrolysis charge $\mathrm{Q}(\mathrm{C})$ per cycle is then associated with the deposited mass Am $(\mathrm{g})$ on the quartz surface by the relation:

$\mathrm{Q}=\mathrm{nF} \Delta \mathrm{m} / \mathrm{M}$

where $\mathrm{n}$ is the number of moles of electrons required to polymerize one mole of monomer units, $\mathrm{n}=2+\delta$, $\mathrm{F}$ the Faraday constant and $\mathrm{M}$ the molar mass of deposited material $\left(\mathrm{g} \mathrm{mol}^{-1}\right), \mathrm{M}=\mathrm{M}_{\mathrm{mu}}+\delta\left(\mathrm{M}_{\mathrm{ClO} 4}+2 \mathrm{M}_{\mathrm{AN}}\right)$ where $\mathrm{M}_{\mathrm{mu}}, \mathrm{M}_{\mathrm{ClO} 4}$ and $\mathrm{M}_{\mathrm{AN}}$ are the molar mass of the monomer unit, the counteranion and acetonitrile, respectively. The assumption that one perchlorate anion is solvated by two molecules of acetonitrile is confirmed by the theoretical value calculated by Marcus [13] using thermodynamic data. So, we can compare the mass variation $\Delta \mathrm{m}^{\text {exp }}$ deduced from Sauerbrey's equation and that extracted from the following equation:

$$
\Delta \mathrm{m}^{\text {th }}=(\mathrm{Q} /(2+\delta) \mathrm{F})\left(\mathrm{M}_{\mathrm{mu}}+\delta\left(\mathrm{M}_{\mathrm{ClO} 4}+2 \mathrm{M}_{\mathrm{AN}}\right)\right)
$$


For values of n comprised between 0.2 and 0.5 electrons and an electrolysis charge Q equal to $58 \mu \mathrm{C}, \Delta \mathrm{m}^{\text {th }}$ can vary between 37.4 and $46.2 \mathrm{ng}$. Since the area of the gold electrode is 0.196 $\mathrm{cm}^{2}$, the quantity of mass $\Delta \mathrm{m}^{\exp }$ is $41.4 \mathrm{ng}$, which corresponds to an amount of charge $\delta$ of $0.33 \mathrm{~mol}$ of electrons.

If we consider in a first approximation that the decrease of mass observed during the discharge process is due only to the number of anions that are expelled from the polymeric matrix, we can link this mass $\Delta \mathrm{m}^{\text {Red }}$ to the charge $\Delta \mathrm{Q}^{\text {Red }}$ by:

$\Delta \mathrm{m}^{\mathrm{Red}}=\left(\Delta \mathrm{Q}^{\mathrm{Red}} / \mathrm{F}\right) \delta\left(\mathrm{M}_{\mathrm{ClO} 4}+2 \mathrm{M}_{\mathrm{AN}}\right)$

For $0.2 \leq 6 \leq 0.5, \Delta \mathrm{m}^{\text {Red }}$ lies between $7.8 \mathrm{ng}$ and $19.5 \mathrm{ng}$. The $\Delta \mathrm{m}^{\text {Red }}$ value deduced from the experiment (Fig. 3) is $10.5 \mathrm{ng}$, yielding a $\delta$ value of 0.27 which is quite similar to that calculated for the oxidation process considering the simplifying hypothesis.

During the dedoping process, the superficially trapped $\mathrm{ClO}_{4}{ }^{-}$counteranions in the polymer are first released into the solution. It has been proved that the incorporation of the cationic species from electrolytic solution occurs when the rate of expulsion of the counteranions becomes weaker than the dedoping kinetics [14]. During the dedoping process, the mass change remains constant between $0.6 \mathrm{~V}$ and $-0.3 \mathrm{~V}$, although the charge goes on decreasing. It turns out that the cations neutralize the anion excess along the polymer chains by creating ion pairs. The mass remaining at the end of each cycle is quite large, suggesting that the cationic species are solvated to a higher degree by acetonitrile than the perchlorate anions. From one cycle to the next the polymer swells and absorbs some solvent molecules and ion pairs. Their release cannot be achieved completely due to the non-equilibrium of ionic species during cyclic voltammetry. Hence, lower kinetics for ionic migration, which would depend on the scan rate, would account for the variation of the slope $\alpha$ observed in Fig. 1 and for the increase in mass activity. We remark that the mass and charge changes reached their respective maxima with a $60 \mathrm{mV}$ shift, which corresponds to a slight delay in ionic movement with respect to the electronic transfer. For later cycles, the mass activity doubled in comparison with the first cycles: this increase in mass activity cannot be explained by the contribution of ionic and solvent absorption alone.

In order to understand the slope changes as the reaction progresses, it is necessary to take into account the formation of oligomers in solution which have a chemical reactivity and a solubility which decreases inversely with their size, as proposed by Roncali et al. [15]. These oligomers would precipitate at a later stage and become trapped in the polymer, creating an increase in mass as experienced by the quartz crystal. Thus we postulate that the second step of polymerization is more likely to be the insertion of oligomers in the polymer matrix without chemical coupling.

From Fig. 2, we can establish the following relation between the film thickness $\ell$ and the electrosynthesis charge $\mathrm{Q}_{\mathrm{e}}$ :

$\ell=(\alpha / \beta)\left(Q_{\mathrm{e}} / \mathrm{dA}\right)$

where $\mathrm{d}$ is the film density, and $\alpha, \beta$ and A have the same meaning as before. If we assume that the film density remains constant, a consequence of a change in the slope $\alpha$ is that the relationship between $\ell$ and Qe is not linear. Further support for this conclusion is provided by scanning electron microscopy [16] which shows, from the metal side to the solution side, an increasing porosity, and therefore a decreasing density, of the polymer film depending on the 
electrosynthesis conditions. Consequently, relation (5) does not yield a linear thicknesscharge relationship as commonly used in the literature [14].

\section{CONCLUSION}

Investigation by QCM has shown that a clear distinction between monomer deposition and ionic movements could be achieved and that a good estimate of the doping ratio $\mathrm{S}$ could be attained $(0.27 \leq \delta \leq 0.33)$. It has been possible to show that the mass change during the anodic process can be attributed to the polymer growth and simultaneous insertion of counteranions necessary to permit charge balance within the film. On the contrary, the mass change during the cathodic process is caused by the preferential insertion of lithium cations over the release of perchlorate anions.

The delay in ionic movement with respect to the electronic transfer accounts for the nonequilibrium of ionic species during cyclic voltammetry, and creates an increasing quantity of solvated ions with the cycle number. The change in polymerization process due to oligomer insertion requires care with film thickness determination, which is not proportional to the electrosynthesis charge.

Finally, this study establishes an empirical basis for further investigations as well as a starting point for studying the kinetics of ionic movements. The QCM is a very sensitive sensor which should make possible the quantification of the diffusion kinetics at the polymer electrode.

\section{ACKNOWLEDGMENTS}

We would like to thank Dr. P. Hany and J.F. Jacquot for technical assistance and appreciated advice.

\section{REFERENCES}

1 M. Slama and J. Tanguy, Synth. Met., 28 (1989) C171.

2 K. Okabayashi, F. Goto, K. Abe and T. Yoshida, Synth. Met., 18 (1987) 365.

3 G. Sauerbrey, Z. Phys., 155 (1959) 206.

4 P. Schulze and K.E. Heusler, Ber. Bunsenges. Phys. Chem., 78 (1974) 601.

5 K.K. Kanazawa and J.G. Gordon, Anal. Chem., 57 (1985) 1770.

6 C.K. Baker and J.R. Reynolds, J. Electroanal. Chem., 251 (1988) 307.

7 J.H. Kaufman, K.K. Kanazawa and G.B. Street, Phys. Rev. Lett., 53 (1984) 2461.

8 K. Naoi, M.M. Lien and W.H. Smyrl, J. Electroanal. Chem., 272 (1989) 273.

9 S. Bruckenstein and M. Shay, Electrochim. Acta, 30 (1985) 1295.

10 D. Orata and D. Buttry, J. Am. Chem. Sot., 109 (1987) 3574.

11 R.J. Waltman, J. Bargon and A.F. Diaz, J. Phys. Chem., 87 (1983) 1459.

12 T. Skotheim, Handbook of Conducting Polymers, Vols. 1 and 2, Marcel Dekker, New York, 1986.

13 Y. Marcus, Ion Solvation, Wiley, New York, 1985.

14 J.L. Baudoin, F. Chao and M. Costa, J. Chim. Phys., 86 (1989) 181.

15 J. Roncali, F. Gamier, M. Lemaire and R. Garreau, Synth. Met., 15 (1986) 323.

16 M.A. Druy, R.J. Seymour and S.K. Tripathy, Polymers in Electronics, ACS Symposium

Series, Vol. 242, The American Chemical Society, Washington, DC, 1984, p. 37. 


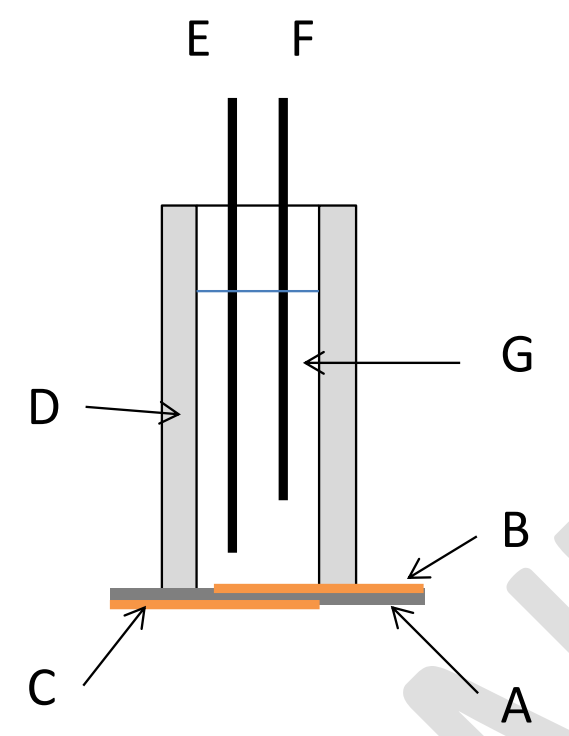

Fig. 1. Scheme of the electrochemical cell used for the QCM experiments. (A) Piezoelectric quartz wafer; (B, C) gold electrodes; (D) glass tube; (E) reference electrode (silver); (F) auxiliary electrode (platinum); $(\mathrm{G})$ electrolytic solution.

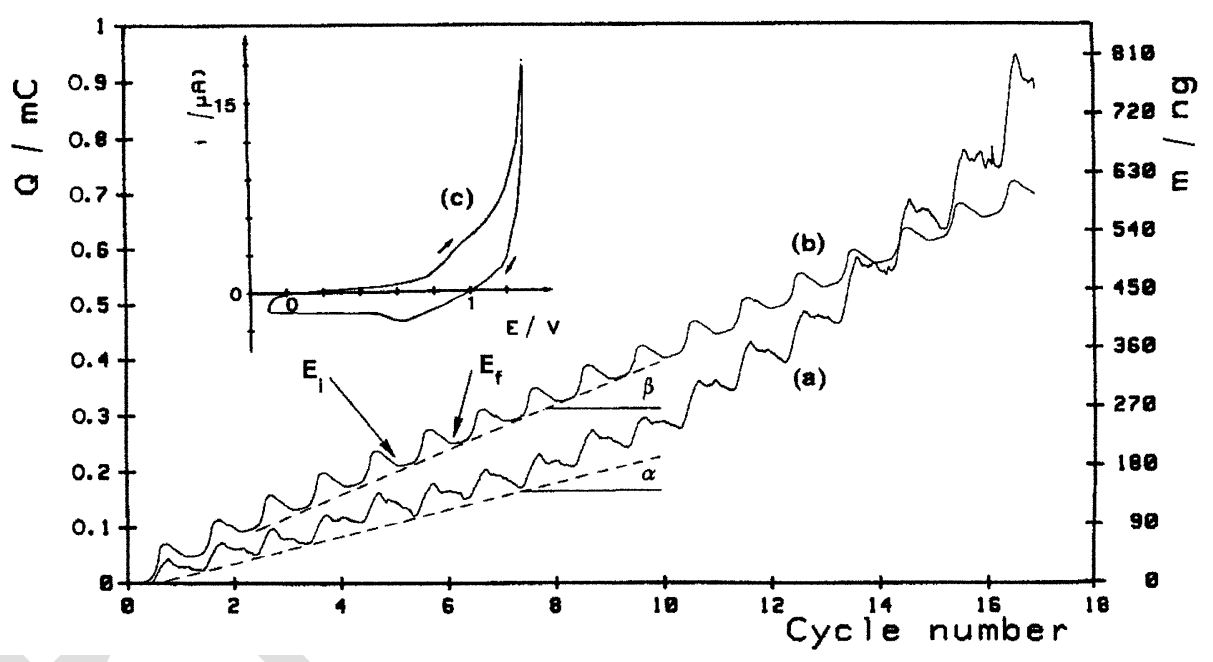

Fig. 2. Mass (a) and charge (b) variations during electrosynthesis of PMT carried out by cyclic voltammetry. Voltammogram (c) recorded during one cycle at $50 \mathrm{mV} \mathrm{s}^{-1}$ between Ei = $-0.1 \mathrm{~V}$ and $\mathrm{Ef}=1.3 \mathrm{v}$. 


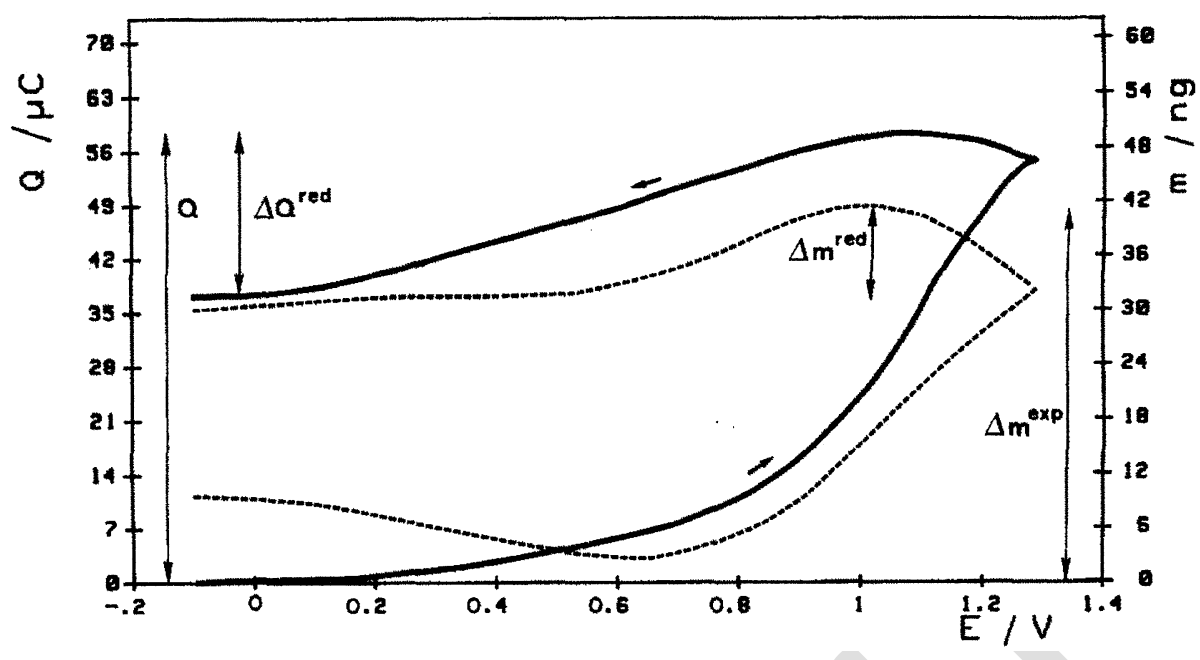

Fig. 3. Average mass (dashed line) and charge (full line) variations versus potential during one cycle ( $\Delta \mathrm{m}$ and $\Delta \mathrm{Q}$ are corrected from the slopes $\alpha$ and $\beta$ defined on Fig. 2). 